\title{
The Making of Relatives: Creating a home away from Home for American Indian Pre-Service Teachers at a Predominantly White Institution
}

\author{
Jioanna Carjuzaa*, Bill Mendoza, and Terry Bradley \\ Center for Bilingual and Multicultural Education, Montana State University, USA
}

\begin{abstract}
Despite the many retention models in place to support American Indian/Alaska Native (Al/AN) students' academic success within Predominantly White Institutions (PWIs) of higher learning, Al/AN student persistence and degree completion continues to be in a state of crisis. Here we highlight the factors that enhance or diminish persistence and describe culturally congruent mentoring approaches. In this article we are focusing on the extraordinary group of American Indian achievers who are members of the Society of INdigenous Educators (SINE) and who, against tremendous odds, persisted and graduated from their teacher preparation program at a land grant institution in the western United States. The SINE mentoring program was created to recruit, retain, graduate, place and provide ongoing support to these pre-service teachers. As is, the status quo at PWIs falls short at best, and in many circumstances diminishes Al/AN students' chances for persistence and completion. By embracing the concept of creating a secondary home away from Home, where students in college have the social, and academic supports necessary, we have conceptualized and developed a culturally congruent, disciplinespecific mentoring program. As key advocates, faculty mentors need a repertoire of knowledge and capacities to support novices' induction into teaching, and to help students navigate institutional, departmental, and programmatic requirements in the university context by developing a constellation of supporters. Given only .4\% of faculty on college campuses are $\mathrm{Al} / \mathrm{AN}$, it is unlikely that $\mathrm{Al} / \mathrm{AN}$ students will have an $\mathrm{Al} / \mathrm{AN}$ faculty mentor in the leadership position of their culturally congruent, discipline-specific mentoring group. This being the case, we identify specific attributes that we recommend for selecting a faculty mentor to serve Al/AN students.
\end{abstract}

\section{Keywords}

Received: March 11, 2019 Accepted: November 20, 2019

Published: December 06, 2019

Copyright: (C2019 Carjuzaa J. This is an open access article distributed under the terms of the Creative Commons Attribution License, which permits unrestricted use, distribution, and reproduction in any medium, provided the original author and source are credited.

\section{Corresponding author:}

Jioanna Carjuzaa, Center for Bilingual and Multicultural Education, Montana State University, USA

E-mail: carjuzaa@montana.edu

\section{Introduction}

Despite the many retention models in place to support American Indian/Alaska Native (Al/AN) ${ }^{1}$ students' academic success within Predominantly White Institutions (PWIs) of higher learning, Al/AN student persistence and degree completion continues to be in a state of crisis. One such retention approach that has been used by PWIs in isolated cases, the Family Education Model (FEM), focuses on replicating the support systems Al/AN students

${ }^{1}$ The authors recognize that there are a variety of terms that are used throughout the literature for Indigenous peoples of North America. Throughout this manuscript we have chosen to use the inclusive term American Indian/Alaska Native (Al/AN) and its established historical and political significance related to tribal nations of the United States. Where deemed appropriate because other scholars have preferred different terms such as, American Indian, Native, Indigenous, and First Nations, we have respected their decisions and our manuscript reflects that. 
experience on reservations and in their respective communities (Heavy Runner \& DeCelles, 2002).

The FEM, a family-centered model, is the foundation of the culturally congruent, disciplinespecific mentoring and advocacy program designed to support Al/AN pre-service teachers at Montana State University (MSU) (Marroquin \& McCoach, 2014; Tachine, Cabrera \& Yellow Bird, 2017; Windchief \& Brown, 2017). In this article we highlight the inception, the evolution, and the continuation of this unique mentoring program as well as share the members' journeys. The idea to explore and develop a mentoring group that would provide academic, personal, career, and financial support arose from Al/AN students' self-identified need for additional, culturally responsive supports. In addition to extending the socio-emotional support necessary to nurture a sense of belonging among Al/AN students, and providing the general introduction to college survival skills, the Society of INdigenous Educators (SINE) was created to focus on the discipline-specific knowledge, skills, and abilities that members felt they needed as pre-service teachers and aspiring professionals. An important realization of the SINE members was their identification of a paradox which they felt was necessary to address in order to successfully complete, or rather 'survive and thrive' their teacher preparation program and job placement. They needed to intentionally invest in themselves beyond, or in lieu of the traditional teacher preparation supports that were provided to all students. Specifically, SINE members organized out of a desire to be equipped with a higher order level of skills, and opportunities in the areas of advocacy, social justice, and multicultural education, and exposure to the shared experience of similarly situated peers. Important to note, is that these students' experiences are not unique to MSU, but rather they are typical for $\mathrm{Al} / \mathrm{AN}$ students attending PWIs nationwide, particularly in selective and competitive institutions or fields. In order to understand the needs of AI/AN students in higher education it is important to delve into how they are often invisible in our education system.

Between 2000 and 2017, the overall AI/AN population in the United States increased by $14 \%$ (from 2.1 million to 2.4 million), yet it still remains around $1 \%$ of the total U.S. population, which is the same percentage of the overall Al/AN K-12 student population (National Center for Education Statistics [NCES], 2019a). Nationwide, the 2016-17 dropout rate for AI/ANs (11\%) was the highest of any other racial/ethnic group, while the Adjusted Cohort Graduation Rate (ACGR) for these secondary students (72\%) was lower than for any other racial/ethnic group, and 12 percentage points less than the rate (84\%) for all students (NCES, 2019a). Consequently, AI/AN students are under represented in institutions of higher education nationally, and to exacerbate this reality, they experience the highest college attrition rates among minority students (Shotton, Oosahwe, \& Cintrón, 2007).

While Al/AN undergraduates consistently (2000-2016) hover around $1 \%$ of all undergraduates in the U.S., the participation and completion rates for Al/AN undergraduate students remains at a critical level (NCES, 2019a). In fact, Al/AN undergraduates have the lowest enrollment as well as the lowest six-year graduation rate (2010-2016 first-time, fulltime students) of any student seeking a bachelor's degree at four-year degree granting institutions (NCES, 2019b). According to the most recently available educational attainment data from 2014, Al/AN students are still reported as being the least likely racial/ethnic group tracked in post-secondary education in the U.S. to graduate from college, with only $13.7 \%$ of those entering college earning a bachelor's degree within six years compared with $52 \%$ for Asians, 34\% for Whites, 20\% for African Americans, and 14.7\% for Hispanics (NCES, 2018).

For the first time in 2012, Montana's population reached just above one million, while the $\mathrm{Al} / \mathrm{AN}$ population is currently over 9\% (Montana Office of Public Instruction [Montana OPI], 2018), and consists mostly of members of twelve tribal nations: Assiniboine, Blackfeet, Chippewa, Cree, Crow, Gros Ventre, Kootenai, Little Shell Tribe of Chippewa, Northern Cheyenne, Pend d'Oreille, Salish, and Sioux. In 2018, 14\% (20,535) of Montana's K-12 students identified as Al/AN, placing Montana among the five states in the country with an Al/AN K-12 population greater than 10\% (Montana OPI, 2018; Civil Rights Data Collection, 2014).

Despite a significant population of $\mathrm{Al} / \mathrm{ANs}$ and recent legislation, particularly the unprecedented Indian Education for All (IEFA) Act, AI/AN students in Montana face similar challenges as their peers nationwide do. In 2018, Montana's Al/AN K-12 four-year ACGR of $67.54 \%$ was lower than the reported graduation rate for any other race/ethnicity in Montana (Growth and Enhancement of Montana Students Graduation [GEMS], 2018). While 14\% of 
Montana's K-12 students identify as Al/AN, the Montana University System (MUS) and Montana's 7 Tribal Colleges serve approximately $6 \%$ undergraduate students that identify as Al/ANs (Montana OPI, 2018). In 2017, the six-year Al/AN graduation rate for students pursuing a bachelor's degree at MSU was $37.7 \%$, compared to the overall MSU rate of $48.7 \%$ and the national rate for Al/ANs at 39\% (NCES, 2019a; NCES, 2019c).

Even though MSU claims to be an institution of choice for Al/AN students, only $4.26 \%$ of the 16,702 student population identifies as Al/AN (Montana OPI, 2018). In the College of Education, Health and Human Development (EHHD) the Al/AN population is slightly higher at $4.4 \%$. Out of the 1434 students enrolled in all EHHD majors, 63 are Al/AN, and out of the 900 students in the Teacher Preparation Program (TEP) there are 31 students who identify as Al/AN (B. Freese, personal communication, August 17, 2018).

In order to address the disparities highlighted here, researchers and practitioners have examined the factors that have enhanced or diminished Al/AN student resiliency, and a number of PWIs have implemented specialized student support groups aimed at improving student persistence and graduation (Marroquin \& McCoach, 2014; Snow Andrade, 2014; Wexler \& Burke, 2011). ). The success of the members of one such support program, the SINE, will be described in detail and its members' voices (quotes appear in italics) are interspersed throughout this article to illustrate how a culturally congruent, discipline-specific mentoring program created a family.

\section{Positionality}

We, the authors of this manuscript, have had our education and professional journeys woven together in many different ways which has led us to this collaboration of the SINE story, sharing all members' lessons and recommendations. We have been involved in collaborative enterprise on a regular basis because of our roles in the SINE, our participation in the American Indian Council (AIC), and our projects within the Center for Bilingual and Multicultural Education at MSU. Specifically, Jioanna Carjuzaa, served as the McNair faculty mentor for Terry Bradley, and also serves as a co-chair on the dissertation committee for Bill Mendoza. Together we have been exploring the implementation of the FEM, the integration of Indian Education for All (IEFA) across the curriculum, as well as how storytelling can be utilized in diverse contexts to effectively build relationships to improve student success.

Jioanna Carjuzaa has over 25 years of experience as a multicultural educator and has worked around the globe. While well versed in the many aspects of cultural diversity, linguistic diversity is her passion. In addition to her heritage Greek language, she has studied several other languages. Diversity has played a key role in her personal and professional life. As a teacher educator and language pedagogical expert, she has worked with over 12,000 students and taught hundreds of courses promoting social justice and educational equity. Currently, she is a Professor at MSU where she has provided IEFA leadership as a scholar and educator within Montana and beyond. As the faculty advisor/mentor for the SINE Cohort she collaborates with many state and tribal organizations to support student success. She is committed to Indigenous language preservation and revitalization efforts and works closely with heritage language speakers. She is actively involved in the professional development of Class 7 Indigenous Language and Culture teachers across Montana. As an ally, she is grateful to serve tribal communities throughout Indian Country.

Bill Mendoza is an Oglala and Sicangu Lakota (Oglala Sioux Tribe) and was born and raised on the Pine Ridge and Rosebud Sioux Reservations in South Dakota. He has earned a Master of Education from MSU and is currently working towards a doctorate in Education Leadership at the same institution. He has experienced, firsthand, through his professional and life experiences, the multitude of strengths and challenges facing American Indian students, educators, and tribes. In addition to being a teacher, principal, and policy advisor, he has worked at the community, tribal, and national level to help foster leadership development and civic engagement among American Indians. Integral to his professional and academic capacity has been his experiences as a student at various tribal colleges and PWIs throughout the country. He has provided support and guidance while currently serving in a leadership capacity for aspiring Native educators in the SINE cohort.

Terry Bradley is Aaniiih (GrosVentre) from the Ft. Belknap Reservation. He was a firstgeneration college student at MSU who majored in Elementary Education, with a Science 
Option. He enrolled at MSU in the Fall 2012 semester, and in his sophomore year, joined the SINE as a member and later served as the Student Advisor. Since his graduation from MSU and even with all of his other responsibilities, he has remained a committed SINE member and attended, participated in, and served in a leadership capacity for all SINE activities. He has played a leadership role in collaboration with the guidance of Jioanna and Bill in planning, organizing and delivering presentations/workshops as well as fundraising. While at MSU, his leadership extended across campus including: Student Associate in the Diversity Awareness Office; Safe Zone Trainer; LGBTQ mentor; coordinator of the Lavender Graduation celebrations, and as the Student Director of Diversity and Inclusion, where he hosted the very first, student-led MSU Diversity Symposium. By participating in this research project and other scholarly activities, we have been proud to support him in his efforts to achieve the goals of the McNair Scholars Program.

\section{Relevant Literature Related to the Case Study}

Here we highlight the factors that enhance or diminish persistence, describe the different views on 'going to college' and 'coming to college', share the power of collective self-esteem, distinguish between the concepts of home versus Home, explore transculturation, and introduce the Family Education Model, nahongvita (loosely, "stay strong" or "dig deep" in Hopi), peer mentoring, and culturally congruent mentoring approaches.

In high school I was told that I would never do anything with my life, meaning I wouldn't go to college or graduate. So, when I graduated from a technology college with my certificate in Welding and Metal Fabrication it felt good knowing I was doing something with my life. This and the fact that my mother being an educator has influenced my educational path. Also, I always heard Plenty Coups' famous quote about education being our greatest weapon and that with education we are equal with the white man. So, in every part of my life I have been surrounded by education. Today my children have the biggest influence on my education. A lot of what I do is for my children. As their first role model, I do my best to be the best dad I can be. (SINE member, Frank)

\section{Persistence}

There is an abundance of literature analyzing the factors that enhance or diminish student resiliency. Although there is no agreed upon definition per se, describing the concept as the ability to face, overcome, and be strengthened or transformed when facing adversity captures what we mean by persistence in higher education (Mosholder, Waite, Larsen, \& Goslin, 2016; Mosholder \& Goslin, 2013; Snow Andrade, 2014; Thornton \& Sanchez, 2010). The research on resiliency in general and some relevant studies on $\mathrm{Al} / \mathrm{AN}$ students in higher education specifically, focus on factors that contribute to students' inability to persist toward degree completion as well as factors that augment students' resiliency (Heavy Runner \& DeCelles, 2002; Joseph \& Windchief, 2015; Kirkness \& Barnhardt, 1991; Marroquin \& McCoach, 2014; Shotton et al., 2007; Windchief \& Brown, 2017).

Factors that impede academic success include: inadequate academic preparation, minimal academic success as reflected in low Grade Point Averages (GPAs), lack of personal motivation, limited family commitment to education, socio-economic related stressors, and cultural incongruities that exacerbate feelings of being an outsider (Mosholder, et al., 2016; Mosholder \& Goslin, 2013; Shotton, et al., 2007).

On the other hand, factors that support academic success include: a strong sense of one's cultural identity and refusal to compromise that identity, accessing relevant and approachable resources, support and opportunities to overcome financial barriers, strong family and community support and involvement, attaining social integration with peers and faculty, a mentor who is an advocate, discipline-specific professional development with a focus on career goals, peer group support and accountability, and nurturing collective self-esteem (Huffman, 2011, 2001; Marroquin \& McCoach, 2014; Shotton, et al., 2007; Thornton \& Sanchez, 2010 ).

Al/AN students frequently report experiencing bias, discrimination, and microaggressions while attending PWIs which can contribute to isolation (Joseph \& Windchief, 2015). The resulting feelings of marginalization often translate into self-segregation as a means of self- preservation. According to Tinto $(1975,1987,1993)$, of the numerous factors that affect AI/AN students' ability to persist, being socially and academically integrated into their campus community, or home away from home, is of key importance. Tinto's model has been criticized when minority students are the focus because of its overreliance on an assimilationist or deficit 
framework, which puts the onus on the students to adapt to the school context, instead of considering changes the institutions of higher learning might make to be more welcoming and less hostile environments for these students. From these discussions, how best to nurturea 'sense of belonging' has been explored (Kirkness \& Barnhardt, 1991; Mosholder \& Goslin, 2013; Tachine, et al., 2017; Tinto, 1975).

\section{'Coming to college' versus 'going to college'}

Kirkness and Barnhardt (1991) distinguish between the concepts of 'coming to college' versus 'going to college.' Whether one views university attendance from the institution's or the students' point of view, the expectations differ greatly. Students viewed as 'coming' to the university are expected to easily adapt to the institution's, "long-standing, deeply rooted policies, practices, programs, and standards," according to Kirkness and Barnhardt (1991, p.96).Conversely, when there is a cultural mismatch between the home culture and the school culture, that transition can be challenging, as is the case for many Al/AN students. In contrast, from the students' perspective of 'going to college,' Al/AN students may have a challenging time adjusting to college life, given their cultural backgrounds and experiences may not have adequately prepared them for the conventional institutional norms and expectations they will face (Benjamin, Chambers \& Reiterman, 1993; Kirkness \& Barnhardt, 1991; Snow Andrade, 2014; Thornton \& Sanchez, 2010).

According to Huffman (2001) "Despite the variation, the major theme included in the conceptual development of cultural conflict is a notion of some discrepancy between the values, behaviors, or political/economic power of those of the dominant status and those of the minority status," (p. 2). These cultural incongruities might leave students feeling alienated and overwhelmed, without familiar cultural connections. For some culturally traditional Al/AN students, experiencing these cultural incongruities may result in them choosing to drop out of college early. Yet there are, as described by Heavy Runner and Marshall (2003), Miracle Survivors, who against all odds, persist. Mentorship in higher education programs that support strong ties to culture can help, according to Marroquin and McCoach (2014). In order to cope with the unfamiliarity of the educational context, AI/AN students who are successful develop a strong network to complement their strong cultural ties (Heavy Runner \& DeCelles, 2002).

\section{Transculturation}

To explore why some $\mathrm{Al} / \mathrm{AN}$ students are able to acculturate and adjust to educational environments more comfortably than others, several researchers have challenged the cultural deficit model and have focused on cultural identity formation (evolving into one's uniqueness) and symbolic interactionism (understanding one's development in roles) to ascertain why certain students are successful instead of focusing on students that experience failure (Huffman, 2011 and 2001; Marroquin \& McCoach, 2014). Huffman (2001) and others assert that a key factor for tenacity in pursuing higher education is having a strong cultural identity and heritage. It may seem counterintuitive or illogical to believe that a transculturated, i.e., the least assimilated AI/AN student who remains more closely tied to his/her traditional culture, would be the student more likely to persevere and complete his/her degree, but that is not the case.

According to Benjamin, Chambers, and Reiterman (1993),

It seems rare, given cultural, worldview, and cognitive obstacles, that any American Indians -especially those who strive to maintain their cultural identity- can succeed in a higher education system dominated by the powerful and persuasive influences of the White majority culture, (p. 25).

Yet, Al/AN students who did not aspire to assimilate, but instead were able to merge their new identity as a student with their cultural self-identity was the key factor defining their success. Marroquin and McCoach (2014) reported, "The findings from our study suggest that the less transculturated students are, the more socially isolated these students feel on campus," (p. 23). In Marroquin and McCoach's (2014) factor analysis, they identified eight factor domains and explained the transculturation theory. Their research revealed that the more transculturated students are, the more likely they are to be academically successful, as reflected in their GPAs, in their exchanges with their peers, and in their determination to persevere (Marroquin \& McCoach, 2014). 


\section{Collective Self-Esteem}

The term collective self-esteem was used by Bettencourt, Charlon, Eubanks, Kernahan, and Fuller (1999) to define the extent to which individuals evaluate their membership in their social groups positively. According to Bettencourt et al. (1999), "... social identification with a context-related group has the capacity to enhance positive adjustment in that context. Development in collective self-esteem with campus groups may contribute to better adjustment to college." (p. 220).

In order to develop a sense of meaning and purpose, secure a sense of belonging, and facilitate the adjustment to college life, students search for a community to join and be part of. "Our group memberships provide us with a sense of belonging, define in part our meaning, and have the prosperity to reflect positively on our sense of self," (Bettencourt, et al., 1999, p. 213). Belonging to a context-related group and evaluating your participation in the group as positive can lead to psychological well-being and has been shown to be a causal influence on both adjustment and persistence (Bettencourt et al., 1999; Shotton, et al., 2007).

Social integration is crucial to creating a feeling of belongingness for Al/AN students whose home environments are often quite different from the university setting and whose unique cultural traditions and beliefs are often not reflected in the institution's practices, policies, and programs. To nurture a sense of belonging, the presence of structured social support systems where students have the opportunity to interact with peers and faculty and form relationships can be crucial to their persistence (Murguia, Padilla, \& Pavel, 1991; Brown, 1997). Other researchers have found that, if social integration can be achieved in an on-campus support group made up of students with similar ethnic/racial backgrounds, students can ease the harmful or detrimental aspects of attending PWIs. An awareness of their interconnectedness with others develops into a sense of interdependence and the growth of collective selfesteem. This relationality is an act of making relatives among peers that are engaging in a shared experience, albeit positive or negative.

Many Al/AN students have identified their association with American Indian clubs, multicultural offices, diversity/inclusion centers and other groups organized to provide social support as a fundamental factor in their success and persistence (Jackson, Smith, \& Hill, 2003). However, several Indigenous scholars have emphasized the importance of creating culturally congruent programming (Heavy Runner \& DeCelles, 2002; Windchief \& Brown, 2017; Tachine, et al., 2017). Where others have advocated for culturally congruent mentoring, the SINE, has expanded its view of mentoring to include: an integration of culturally responsive pedagogy, an induction into the teaching field, an adoption of advocacy, and a focus on career goals. Drawing from a variety of mentoring methodologies designed to be effective for Al/AN students, this novel, holistic mentoring approach adopted by the SINE, has proudly supported the members' completion of the TEP, graduation from the university, job placement, and continual career mentoring. Furthermore, the SINE has helped its members create an image of themselves that refutes past negative experiences with failure.

\section{Mentoring Programs}

In 2014 the Obama Administration, as an extension of the My Brother's Keeper Alliance, identified mentoring as a national priority and became a key component of the White House, My Brother's Keeper Initiative, which focused on the success and development of boys and young men of color (Executive Office of the President, 2014a). Also, in 2014, the Obama Administration launched The Generation Indigenous (Gen-I) initiative which focused on a comprehensive approach to education, health and nutrition, juvenile justice, housing, and youth engagement of $\mathrm{Al} / \mathrm{AN}$ youth. A key element of the Gen-I youth engagement component was increasing access and opportunity to mentoring Al/AN youth (Executive Office of the President, 2014b). Mentorship's positive influence on decision making, aspirations, and outcomes for youth across the U.S, was also highlighted in 2014 by the policy and advocacy organization, MENTOR: The National Mentoring Partnership and was recommended as a key strategy to address issues and problems currently facing colleges and universities across the country (Bruce \& Bridgeland, 2014). For example, mentoring initiatives contribute to the Completion Agenda, a national movement led largely by policymakers to increase college completion rates through improved policies and practices (The College Board, 2013).

Consequently, mentoring programs and associated efforts were considered to be effective means of supporting student development and academic success. Some notable outcomes of 
mentoring undergraduate students include increased academic performance as measured on exam scores and in GPAs, and involvement in program related activities (Benjamin, et al., 1993; LaFramboise, Hoyt, Oliver \& Whitbeck, 2006). Many researchers believe that the creation of more support groups would improve the retention of Al/AN students by helping them adapt to the university setting (Jackson, et al., 2003). We argue that just increasing the number of support groups is inefficient. Instead, the emphasis should be on offering culturally congruent quality mentoring programs.

\section{MSU Student Support Services}

At MSU, we foster an institutional culture and commitment to high-quality mentoring. Several of our mentoring programs designed to support Al/AN students are described in Appendix A. MSU currently boasts the highest enrollment and retention rates for AI/AN students in the Montana University System; they are a diverse group representative of over 60 tribal nations. No matter which college they are admitted in, or what major they declare, the Native American Studies (NAS) department is their homebase on campus. NAS was established to provide and advance quality education for and about American Indians of Montana, the region, and the nation. In addition to the traditional functions of an academic department, NAS places a high priority on providing student support programs and services, reflecting a strong commitment to $\mathrm{Al} / \mathrm{AN}$ student retention and success. In fact, any Al/AN student who decides to attend MSU can explore a variety of programs within the extensive support network.

Housed in the NAS department, the American Indian Council (AIC) has been in existence for over 60 years. According to the AIC By Laws (2014), the AIC was established to: recruit high school and transfer students to attend MSU; assist new students in their adjustment to college life; provide an environment that respects and promotes scholarship in accordance with students' cultures and customs; work with students through promotion of extra-curricular activities that bridge MSU with the greater community and its Al/AN residents (Jim Burns, personal communication, February 4, 2014). The AIC offers academic advising, personal counseling, inspiration and hope to $\mathrm{Al} / \mathrm{AN}$ students. For a list of the achievements, comprehensive services, initiatives, and resources AIC provides to promote students' academic success in addition to the numerous cultural events which it hosts, see Appendix A.

As long-standing and successful as the AIC is, there was a need to establish additional, specialized mentoring programs on campus to support Al/AN students pursuing a degree outside of NAS, especially in academically demanding, competitive fields. During the 10+ years the SINE faculty advisor/mentor served as co-advisor to AIC, she was greatly concerned to observe the poor track record the Department of Education had in graduating AI/AN students. Following discussions with one of her undergraduate McNair Scholar mentees who was interested in obtaining personal support (i.e., child care, travel assistance, coverage of professional fees, etc.) during her pursuit of a teaching license, it became clear to the SINE faculty advisor/mentor and the student that much more than the ancillary support services were needed. The SINE joined the ranks of the numerous culturally congruent, discipline-specific mentoring programs that are successful at MSU: EMPower, AIRO, MAP, which are operated through the College of Engineering and COOP in the College of Nursing, to name a few. Read more about the success of these support groups in Appendix A.

In creating the SINE, we incorporated Indigenous values from a variety of mentoring models in higher education. We have built upon the FEM, nahongvita, peer mentoring and culturally congruent mentoring. In their seminal article, Kirkness and Barnhardt (1991) highlighted the Indigenous values that support student success in higher education and are present in the mentoring models mentioned here which are described later. Their research provides a template which can be used for negotiating inequities in higher education institutions in general and PWIs specifically. Their study sought to transform the relationship between AI/AN students and the faculty, staff, and administrators they interact with. It focused on the mismatch of perspectives and the effect on pedagogical practices. Their findings are applicable to efforts to improve mentoring practices between the academy and tribal members. Kirkness and Barnhardt (1991) identified four requirements for promoting more equitable relationships and interactions between Indigenous peoples and the academy which include respect, relevance, reciprocity, and responsibility. They described these concepts in relationship to what it is that $\mathrm{Al} / \mathrm{AN}$ students need to succeed in higher education." In more human terms, with an emphasis on the need for a higher educational system that respects 
them for who they are, that is relevant to their view of the world, that offers reciprocity in their relationships with others, and that helps them exercise responsibility over their own lives," (Kirkness \& Barnhardt, 1991, p. 95)

Despite the fact that all 4Rs relate to the dilemma of determining appropriate and effective mentoring strategies for Al/AN students, many Indigenous scholars emphasize the importance of relationships, not just current human relationships, but the connection Indigenous peoples have to their ancestors, the future generations, nature, and to the land (Wilson, 2008). When Wilson (2008) polled his colleagues, "Several stated that the relational way of being was at the heart of what it means to be Indigenous," (p. 80). This value on making relatives is a tenet of tribal worldviews.

\section{Mentoring Models}

Although scholars have identified the above-mentioned factors which negatively impact students' chances for success, we see this focus on the limitations and/or shortcomings of the individual student and the need for him/her to change as contributing to a myopic, deficit definition of the circumstances surrounding AI/AN students' inability to persist. Instead of focusing on students' failure to persist and graduate from college, we focused on the qualities and experiences of students who have been able to break the at-risk cycle and succeed. Several developers of models such as FEM, navongvita, peer mentoring, and culturally congruent mentoring have identified the individual and environmental factors that contribute to student persistence and the role culturally congruent mentoring plays in Al/AN student success.

Although in creating the SINE we have drawn from the four models mentioned here, in our culturally congruent, discipline-specific mentoring approach we have focused more on the vital role of the faculty advisor as a mentor and advocate in relationship to his/her mentees as well as the roles of the student advisor/mentor and the group's members.

The meaning of the SINE has changed from a small cohort to a family of support, care, appreciation and love from some of a few unlikely people that I would have never had the chance to cross paths with to continue on a similar path with having them impact my life for the betterment of my knowledge and our shared experiences. (SINE Member, Wilma)

\section{Family Education Model}

In 1997, in order to address the high rate of attrition that Al/AN students experience in higher education, American Indian educators, social work professionals, and academic advisors from five institutions of higher education in Montana, developed a culturally attuned program which has become known as the FEM (Heavy Runner \& DeCelles, 2002). By focusing on factors that contribute to students' educational persistence, the FEM promotes empowerment, family and community support, and strong cultural ties to enhance resilience. It was the first program of its kind in higher education. Heavy Runner and DeCelles (2002) found that if we replicate the extended family structure students are familiar with in their reservation communities within the college environment, it enhances the American Indian student's sense of belonging and leads to higher retention and graduation rates. The sense of belonging that results, promotes a strong, deep sense of commitment to the group and an appreciation for the unique group members' personalities, their individual experiences, and their leadership skills which is captured in the following quote, "As determined in traditional family structures, the desire to help others by sharing knowledge emerged from Plains Indian philosophy to become a vital theme for dynamic leadership in the FEM," (Heavy Runner \& DeCelles, 2002, p.33).

Being a member of this cohort has helped me a lot. This group means the world to me. It's not just the money to take care of finger printing or background checks. But true support. Having others to look to for help when school gets tough. Support when teachers are not being fair or not being culturally sensitive. This group has been there. Now I have 5 people I can go to when I need help when I need advice or when I need a laugh. The other members and the advisor are now my family. I would be having a harder time without this group. So, it means the world. I am very grateful and blessed to be a part of the SINE group. (SINE member, Frank)

\section{Nahongvita}

Students approach the challenges of college from their distinctive cultural base; this is particularly true for Al/AN students (Benjamin, Chambers, \& Reiterman, 1993). In the nahongvita mentoring model, students rely on their unique experiences to define lower-case$\mathrm{h}$ home, the secondary academic home they create in their educational pursuits, compared to 
capital-H Home, their Home consisting of family, community members and their primary cultural resources (Windchief \& Joseph, 2015). Students need support and guidance when transitioning between Home and home. According to Windchief and Joseph (2015), negotiating and adapting values is part of 'coming to college' that many students may experience, but this evolving process can be more challenging for Al/AN students than their mainstream counterparts. The nahongvita (self-empowerment) model, highlights the transition students go through while moving from Home to home defining their cultural identity and cultivating a sense of belonging.

The vast majority of Al/AN students may feel an obligation and desire to go home frequently to participate in ceremonies, socio-political activities, funerals, and/or cultural celebrations more so than their peers. They are members of close-knit extended families where the responsibility for interrelationship and interdependence impacts everyone profoundly; so, when something happens in their communities, it impacts everyone. These family ties at times may come into conflict with educational commitments. If students take prolonged absences, they often face detrimental consequences for missing their classes. When students have a strong sense of self and they maintain close ties to their community, they can rely on someone at Home to fulfill community responsibilities while they focus on school. This division of responsibility frees the students to see that, "... the attainment of post-baccalaureate credentials is linked to their connection to their Indigenous community," (Windchief \& Joseph, 2015 , p. 85). In turn, this connection to Home enables students' self-empowerment and allows individuals to change their physical spaces without compromising their identity.

MSU hasn't done much. They provide the campus and professors, but some people lack in the area of support and caring. I've been seen by the campus as a number and a way to help their numbers. Most of the support I have gotten has been from looking elsewhere and to the SINE. The SINE has a great support system. They become family within minutes and understand the struggle that we as Native students go through. The SINE then does everything possible to help you as a student. The amount of knowledge that the SINE offers eases the stress of school life. They make it fun and go above and beyond for each member. I really love SINE! (SINE member, Frank)

\section{Peer Mentoring}

Whether it involves seasoned faculty serving as mentors for junior faculty, or students serving as mentors for fellow students, peer mentoring is a relationship between individuals, whereby the more experienced person(s) is(are) committed to providing developmental support to the other, less experienced person(s). Peer mentoring programs, which match students with students who are similarly situated and have had shared experiences, have been implemented in higher education institutions across the country and have been suggested as particularly important for under-represented and first-generation college students (Collier, 2015). The experience of Al/AN students labeled as non-persisters, often report feeling disconnected and underserved on campuses, while persisters often credit a peer-mentoring program as not only integrating them into the university, but such association is also credited for helping them develop critical support networks (Shotton et al., 2007). Villalpando (2003) reported empirical quantitative evidence indicating that same-race affiliation benefits students of color. In this qualitative follow-up study, he explained the important, yet disconcerting role ethnic/racial support groups play at PWls, "peer groups empower and nourish academic success and foster the development of a critical cultural consciousness of understanding the members' condition as racialized students within the academy," (p.633). These support groups for minority students are often criticized, as Villalpando (2003) points out,

These same-race peer association patterns typically do not attract much attention when it is white students who are hanging out together. However, when students of color are observed associating with each other, their same-race affiliations are lamented in the public and private discourse as the cause for the racial balkanization of college campuses, (p. 619).

Nonetheless, these programs can help students with networking and socializing for both academic and social activities. Although same-race mentoring has traditionally been viewed with reservations because of its possible segregationist consequences, several authors have argued for its utility (Marroquin \& McCoach, 2014; Tate \& Schwartz, 1993; Villalpando, 2003). Even though several colleges and universities have implemented support programs that involve peer-to-peer mentoring components that seek to integrate minority students both socially and academically, the development of such programs has rarely included the input of 
respective Al/AN communities or students. One notable exception is the American Indian Retention Program (AIRP) of the Student Recruitment and Retention Center (SRRC) at UC Davis (American Indian Retention Program, 2018). Unlike other retention programs, AIRP was developed and administered by a group of American Indian students. This studentinitiated, peer- mentoring retention program was created to meet the unique needs of the American Indian, Indigenous, and First Nations students at their institution. By providing services geared toward the participants' academic success and personal development, this program adds to the limited knowledge base on the factors influencing American Indian student success and confirms the effectiveness of peer-mentoring programs in enhancing $\mathrm{Al} / \mathrm{AN}$ student integration and persistence in higher education institutions. Given the potential of peer-to-peer mentoring programs, particularly for vulnerable populations such as Al/AN students, more application of these strategies should complement structured support groups.

\section{Culturally Congruent Mentoring}

According to Windchief and Brown (2017) culturally congruent mentoring is evident in an institutional context where $\mathrm{Al} / \mathrm{AN}$ students do not have to assimilate nor compromise who they are in order to succeed, persist and graduate. They highlight how a culturally congruent mentoring model for Al/AN graduate students can help them maintain their cultural identity while pursuing degrees in science, technology, engineering and math (STEM). With this Indigenous mentoring model, they ignore the common deficit discourse and instead focus on culturally congruent mentoring which includes the following, "attention to place, meaningful relationships that start with committee members, navigating multiple institutional contexts and students' Indigenous identity location," (Windchief \& Brown 2017, p. 330). Like the FEM and nahongvita model, this culturally congruent mentoring model embraces Indigenous identities and relationships. Although Windchief and Brown (2017) were advocating for institutions to create culturally congruent mentoring programs for graduate students in STEM fields, we found their advice to be applicable for Al/AN pre-service teachers. Therefore, in establishing the SINE, we were sure to validate our members' life experiences, value their cultural heritages, and provide them with opportunities to build relationships with peers and mentors.

It has changed so much over time. When I first joined the SINE, I thought we would only be learning how to be better teachers. We have learned that and so much more. Each individual person will have challenges - personal as well as professional. Each lesson we learn will help us but with these challenges we are not alone. We are a family and all of the SINE group members look to each other for help and strength, like a family in our home away from Home. (SINE member, Franny)

\section{Methodology Research Design}

Several research studies on Al/AN students have relied on quantitative methods and are often based on data collected from surveys. Hoffman, Jackson, and Smith (2005) argue that findings based on quantitative methodology are frequently framed within a positivistic paradigm that may or may not align with Al/AN worldviews. Moreover, quantitative approaches often impose a Eurocentric deficit framework that can be interpreted as being in direct conflict with Indigenous knowledge and wisdom (Bernard, 2012; Tierney, 1992). Thus, a qualitative methodology may be more appropriate for understanding and capturing the experiences of Al/AN students and was employed here.

Qualitative case study methodology was used to explore the persistence of Al/AN preservice teachers and describe how mentoring actually influenced and shaped the members' experiences as they participated in a unique culturally congruent, discipline-specific mentoring program at MSU. This approach is particularly appropriate when the phenomenon under study is bounded, of 'special interest,' and complex (Stake, 1995, 1978; Yin, 2002). As Stake (1995) proposes, we have taken a more flexible stance focused on what is studied (the SINE group) as opposed to the way it was studied (the method).

Although the study was narrowly focused, it allowed us to combine both objective and subjective data to describe and provide a detailed picture of the membership, function, challenges, and successes of the SINE members. We collected in-depth data in a real-life context over a six-year period, from 2012-2018. We employed a multi-modal data collection approach including: formal interviews, written surveys, informal conversations, participant observations, a review of documents and archived records, and an exploration of artifacts and numerous observations in professional/academic as well as personal settings (see Tables 1 and 2). Pseudonyms were assigned to each of the SINE members to protect their anonymity. 
The SINE member quotations integrated throughout the manuscript were gathered over six years of the case study and were selected for their representation of the collective views of the SINE members. Students provided their consent to the inclusion of their contributions.

This form of inquiry enabled a comprehensive and in-depth insight into a diverse range of issues across the varied education majors and areas of specialization the members were pursuing (Creswell, 2014; Creswell, Hanson, Plano, Vicki \& Morales, 2007; Denzin,\& Lincoln, 2011; Harrison, Birks, Franklin \& Mills 2017). The numerous social, cultural, and organizational contextual variables explored were significant to understanding the case because of the diverse experiences the members had.

We used an holistic approach to analyze all of the data and drew conclusions from the entirety of the corpus. In this intensive analysis of the factors that supported or diminished the undergraduate SINE members' success and persistence, we discerned that without membership in a culturally congruent, discipline-specific mentoring program, students would have felt vulnerable and at great risk of not completing the teacher preparation program.

This case study served to examine mentoring efforts designed to encourage resilience in $\mathrm{Al} / \mathrm{AN}$ students attending PWIs. We explored the FEM, nahongvita, peer mentoring, and culturally congruent, discipline-specific Al/AN mentoring models which are believed to effectively support Al/AN students' sense of belonging, appreciation of their cultural norms, and experiences. This case study research methodology is a combination of both the illustrative and critical approaches to case study research and was used so that we could 'illustrate' or describe Al/AN students' experiences at a PWI in such a way that we could paint a picture of the situation for fellow educators involved in student support services and introduce terminology and concepts associated with the various models of culturally congruent mentoring programs used to support minority students in higher education (Denzin, \& Lincoln, 2011; Harrison, Birks, Franklin \& Mills, 2017). The experiences of the SINE members may be examined to raise questions or challenge previously held assertions regarding best practices and it also offers how institutions of higher learning might best identify how to better serve their Al/AN students. This research has shed light on the deficit model that not only blames the student for the inability to succeed academically but also relinquishes the responsibility of institutions to be culturally responsive to vulnerable populations and has led to the creation of new hypotheses that can be explored and tested later, namely how can institutions of higher learning provide widespread, ongoing culturally congruent mentoring in all fields including highly competitive disciplines as well as what attributes the faculty and student advisor/ mentor for a culturally congruent, discipline-specific mentoring group should possess.

Although, concerns about the reliability, validity and generalizability of the results may arise, we believe using the case study methodology here has allowed us to understand complex issues in a natural context. The disadvantage to this case study is that it was not large scale, nor is it easily replicated without commitment from multiple levels of leadership. This case study was designed to provide information that lead to an in-depth understanding of behaviors, processes, practices, and relationships in context and has resulted in the formation of the hypotheses listed above for future research (Denzin \& Lincoln, 2011).

It went from being just a group to get incentives and trips into gaining more family. I didn't think I would have people who supported me the way this group has. To me SINE means family or togetherness. (SINE member, Ryan)

\section{The SINE Overview}

At MSU, the field-based Teacher Education Program (TEP) is grounded in the liberal arts and contextualized in professional preparation coursework based on current educational theory and praxis. In addition to the course work, carefully structured and supervised field experiences are integrated throughout the program so there are ample opportunities to use theories and methods taught on campus and apply them in a K-12 classroom setting. The integration of theory and practice allows students to develop and demonstrate a breadth of knowledge, competencies and professional commitment.

Prior to the creation of the SINE, there were no departmental support services provided specifically to guide Al/AN students through the program requirements, help them deal with cultural insensitivity, and prepare them to enter the conservative, sometimes unwelcoming teaching field. The Department of Education does have an Advising Center and a Teaching 
Licensure Office to help pre-service teachers, but $\mathrm{Al} / \mathrm{AN}$ pre-service teachers did not experience these efforts as adequate support due to their isolation and a lack of cultural congruence.

Through the SINE we have supported Al/AN students enrolled as Elementary Education majors as well as those individuals enrolled in the numerous majors across campus designed to prepare students for $\mathrm{K}-12$ and secondary certification, in addition to recruiting additional students interested in pursuing a teaching career. Looking at other successful support programs designed specifically to promote AI/AN student success at MSU, the SINE was designed to be holistic, comprehensive, on-going, and discipline-specific. While participating in the SINE, our AI/AN students were working towards completing their TEP as well as successfully transitioning from student to beginning teacher.

The SINE is a professionally focused mentoring group for AI/AN students who want to become teachers. The mission of the SINE is to increase opportunities for AI/AN students enrolled in the TEP at MSU by providing culturally congruent, discipline-specific mentoring and advocacy. Specifically, the SINE provides, academic, personal, professional, and financial support that furthers the recruitment, retention, graduation, and placement of $\mathrm{Al} / \mathrm{AN}$ teachers so as to increase diversity in the K-12 teaching corps in Montana and ensure the attainment of educational access and opportunities. A guiding value of the SINE was the empowerment of its members through the strengthening of their cultural identities.

Several SINE members shared that they did not have American Indian teachers as role models during their educational journeys and therefore, were motivated to enter the teaching field and add to the diversity of the teaching corps.

I wanted to become a teacher because I wanted to be the teacher I had wished for as a young public school student. (SINE member, Wilma)

School was my safe haven while having a violent and difficult homelife. Teachers were the gatekeepers. In the classroom, I was given the opportunity to just be a kid to explore, investigate, test, fail, succeed, and learn. For a majority of my life, my only advocates were my teachers and I wanted to offer that to others. I wanted to be a teacher so I could offer the same hope I was given to a child who may need it just as much as I did. (SINE member, Brock)

I always wanted to be a teacher because there are hardly any Native teachers, so I wanted to be one of them. (SINE member, Franny)

There has been a lot of research on the positive effects of having tribal members serve as teacher role models for American Indian students in the K-12 system (Cleary \& Peacock, 1998; Lomawaima, 1995; Pewewardy, 2008). Of the 3.8 million K-12 public school teachers nationwide in 2015-2016, the Al/AN total number of teachers was a mere $.4 \%$, while the breakdown of other teachers by race is: $80 \%$ White, $6.7 \%$ Black, $8.8 \%$ Hispanic, and $2.3 \%$ Asian during the same academic year (NCES, 2018). The percentage is similar in Montana where only $3.7 \%$ of the $\mathrm{K}-12$ teaching corps is $\mathrm{AI} / \mathrm{AN}$ and each SINE member comprehended the sense of urgency with which they needed to enter their chosen profession. Thus, the SINE was created to include career mentoring and networking opportunities in the context of teaching (a specific discipline) in order to increase the participation of this greatly under represented group in the $\mathrm{K}-12$ teaching corps.

Since the inception of the SINE six years ago, the number of AI/AN students in the TEP has remained steady at approximately 30 with the total number of students enrolled in the program fluctuating between 1100-600 students. (B. Freese, personal communication, August 17, 2018). This is in line with the decreased enrollment in teacher preparation programs and the teacher shortage nationwide. Over the course of a decade, only a handful of AI/AN students successfully completed the TEP and secured employment as classroom teachers. The AI/AN students in the TEP were actively looking for structured support, which led to formal conversations about creating a mentoring program. Given there was no designated funding to provide the additional supports we deemed necessary to positively impact Al/AN pre-service teachers' persistence, graduation and job placement, the faculty advisor/mentor decided to pursue funding resources including internal and external grants.

Once awarded funding, Wanji Oyate (One Tribe), the inaugural education cohort for Al/AN students, got underway in 2012. Two years later, under new student leadership, the rebranded Society of INdigenous Educators (SINE), was renamed to reflect the diversity of tribal nations represented by its members, and was established in 2014. During the fall 2016 semester the SINE applied for and received Organizational recognition by the Associated 
Students of Montana State University student government; we filed for and were awarded recognition as an official student organization with a faculty advisor, club officers, and the opportunity to apply for financial support for our activities.

Emphasis was placed on creating a culturally congruent environment where Al/AN students pursuing a teaching career, 'feel at home' in our PWI by reaffirming student members' cultural heritages, focusing on culturally responsive pedagogy, and embracing the 4 R's: respect, relevance, reciprocity, and responsibility as laid out in the seminal article by Kirkness and Barnhardt (1991). By helping students make a successful transition in adjusting to college life, learning about resources on campus while discovering the ins and outs of navigating MSU, receiving advisement and assistance in registering for classes, improving time management and study skills, making plans for short- and long-term academic goals, we engaged in the act of making relatives while also building an Al/AN community of educators.

Most mentoring programs are focused on socio-emotional and general academic support. While some mentoring programs focus on professional socialization and content-specific mentoring (Achinstein \& Davis, 2014), few are designed to be both culturally congruent, discipline-specific and focused on preparing novice teachers for the profession they will be inducted into by advocating for educational equity and social justice. Not only is the SINE culturally congruent, but it focuses on a specific professional area, teaching as a discipline. Unfortunately, with limited numbers of pre-service teachers and a limited pool of faculty advisors (who are also often inadequately prepared) to warrant grouping of mentees for specific content-areas (i.e., a separate health enhancement, art, and/or science content focus), we have provided comprehensive, inclusive, discipline-specific mentoring for the SINE members as a cohort (i.e., all Native education majors grouped together; elementary, K12 and secondary majors). As Achinstein and Davis (2014) describe, having a mentor who is a teacher educator with $\mathrm{K}-12$ teaching experience allowed for this focus on a variety of content and pedagogical particulars.

One curriculum area that was important to the preparation of the SINE members as preservice teachers was Montana's Indian Education for All (IEFA), an unprecedented reform effort $45+$ years in the making. This culturally responsive pedagogical approach is for all students, at all grade levels in all subjects. In 1972, the delegates of the Constitutional Convention included language in the constitution specific to preserving the cultural integrity of Montana's 12 tribal nations. Article X, Section 1 (2) pledged, "The state recognizes the distinct and unique cultural heritage of American Indians and is committed in its educational goals to the preservation of their cultural integrity" (Mont. Const. art. X, §1). The constitutional language was finally codified in 1999 when the Legislature passed MCA20-1-501, now known as Indian Education for All (IEFA). It requires that,

... every Montanan ... whether Indian or non-Indian, be encouraged to learn about the distinct and unique heritage of American Indians in a culturally responsive manner all school personnel should have an understanding and awareness of Indian tribes to help them relate effectively with Indian students and parents Every educational agency and all educational personnel will work cooperatively with Montana tribes ... when providing instruction and implementing an educational goal (Mont. code. Ann. ttl. 20, ch.1, pt. $5 \S 1$, 1999).

All Montana educators have legal obligations, ethical commitments and instructional responsibilities to integrate IEFA content across the curriculum. Since the SINE members all aspired to be teachers, it was important to review the expectations of this culturally responsive pedagogical model by addressing the evolution of this legislative mandate, Essential Understandings created to serve as a framework, professional development opportunities, challenges to implementation, and successes in lesson/unit plans that integrate IEFA. It was also important to review the challenges and resistance some educators express in integrating Indian education and the misunderstanding in Native teachers' role in its implementation.

This focus resulted in numerous opportunities for the SINE members to present on campus and at Indian education conferences across the state, region, and country. Achinstein and Davis (2014) identified factors that are necessary in beneficial content-focused mentoring that support novices' growth including: developing content pedagogical skills, developing pupils' disciplinary thinking, and exploring assessment as well as providing mentees with the opportunity to interact and engage in professional learning dialogues with teaching 
professionals in their specific teaching disciplines. A unique aspect of the SINE was that as Al/AN pre-service teachers, the SINE members were exposed to IEFA in a safe and empowering environment, free of stereotypical assumptions about their understanding of IEFA. To a degree, the SINE members were able to gain practice in integrating IEFA content, while also experiencing a deeper level of reflection and analysis than they would have otherwise experienced in isolation within their general teacher preparation coursework.

As a Native American student majoring in education, I am looked at as the expert for all Native American heritages, cultures, and traditions. I barely know my own tribe's history and culture, let alone all tribes' histories and cultures. I have found out that even if I preface my comments with, "I am no expert' or 'this is just what I think on the matter', my peers and professors take what I say as fact. Yet on the other hand, when I critique something and my opinion is unwanted or unpopular, my peers and professors just see me as the angry Native who is just mad at everything. I am constantly walking in two worlds on this campus and in the classroom. (SINE member, Brock)

\section{The SINE Culture}

Storytelling was a key way that the SINE members shared their life experiences with each other and with audience members when presenting (Wilson, 2008). Specifically, we embraced the role of storytelling in our day-to-day interactions with each other, our formal presentations, and our informal conversations with others as a way to share autobiographical experiences. (Shotton et al., 2007). Everyone involved in the SINE mentoring relationship felt a sense of belonging and acceptance through sharing their unique educational journeys, personal experiences and academic pursuits.

The SINE's meetings entailed weekly working lunches and regular virtual communications throughout the week. Like most student groups, the membership rates were not static within the organization. Yet, unlike most student groups, the group met year-round, during the academic year and during breaks and holidays. During peak times of the year, membership ranged from 10-14 members, with five members establishing and developing a home away from Home that embodied family and community (see Table 1). These five were the heart of the organization.

Table 1. Description of core SINE members.

\begin{tabular}{|c|c|c|c|c|c|c|c|}
\hline Member & $\begin{array}{l}\text { Tribal } \\
\text { Affiliation }\end{array}$ & Major/Minor & $\begin{array}{l}\text { Degre e } \\
\text { Earne d }\end{array}$ & $\begin{array}{l}\text { Years in } \\
\text { SINE }\end{array}$ & $\begin{array}{l}\text { Special } \\
\text { Recognition/A } \\
\text { wards }\end{array}$ & $\begin{array}{l}\text { Experience } \\
\text { Highlights }\end{array}$ & $\begin{array}{l}\text { Parent } \\
\text { or } \\
\text { Single }\end{array}$ \\
\hline Brock & Aaniiih & $\begin{array}{l}\text { Elementary } \\
\text { Education w/ } \\
\text { Science } \\
\text { Option }\end{array}$ & $\begin{array}{l}\text { B.A. } \\
\text { Elementary } \\
\text { Education }\end{array}$ & 4 & $\begin{array}{l}\text { McNair } \\
\text { Scholar, } \\
\text { Student } \\
\text { Director of } \\
\text { Diversity } \\
\text { and } \\
\text { Inclusion } \\
\end{array}$ & $\begin{array}{l}\text { Migrant } \\
\text { Summer } \\
\text { School } \\
\text { Teaching }\end{array}$ & Single \\
\hline Wilma & Aaniiih & $\begin{array}{l}\text { Health } \\
\text { Enhancement } \\
\text { w/ Coaching, } \\
\text { Art, and NAS } \\
\text { Minors }\end{array}$ & $\begin{array}{l}\text { B.S. Health } \\
\text { Enhancement } \\
\text { K-12 }\end{array}$ & 5 & $\begin{array}{l}\text { Montana } \\
\text { Traditional } \\
\text { Games } \\
\text { Instructor } \\
\text { Certified }\end{array}$ & $\begin{array}{l}\text { Secondary } \\
\text { Substitute } \\
\text { Teaching }\end{array}$ & Single \\
\hline Frank & Crow & $\begin{array}{l}\text { Health } \\
\text { Enhancement } \\
\text { w/ Coaching } \\
\text { and NAS } \\
\text { Minors }\end{array}$ & $\begin{array}{l}\text { B.S. Health } \\
\text { Enhancement } \\
\text { K-12 }\end{array}$ & 5 & $\begin{array}{l}\text { Montana } \\
\text { Traditional } \\
\text { Games } \\
\text { Instructor } \\
\text { Certified }\end{array}$ & $\begin{array}{l}\text { Secondary } \\
\text { Health } \\
\text { Enhancement } \\
\text { Teacher; } \\
\text { Track Coach }\end{array}$ & $\begin{array}{l}\text { Parent } \\
\text { of } 3\end{array}$ \\
\hline Ryan & Blackfeet & $\begin{array}{l}\text { English Film } \\
\text { Studies from } \\
\mathrm{U} \text { of M and } \\
\text { English } \\
\text { Teaching } \\
\text { Certification } \\
\text { from MSU }\end{array}$ & $\begin{array}{l}\text { B.A. English } \\
\text { Film Studies - U } \\
\text { of M } \\
\text { English }\end{array}$ & 5 & $\begin{array}{l}\text { Montana } \\
\text { Traditional } \\
\text { Games } \\
\text { Instructor } \\
\text { Certified }\end{array}$ & $\begin{array}{l}\text { Immersion } \\
\text { School } \\
\text { Teacher; } \\
\text { Alternative } \\
\text { High School } \\
\text { Teacher }\end{array}$ & $\begin{array}{l}\text { Parent } \\
\text { of } 2\end{array}$ \\
\hline Franny & $\begin{array}{l}\text { Northern } \\
\text { Cheyenne }\end{array}$ & $\begin{array}{l}\text { Art } \\
\text { Education w/ } \\
\text { NAS Minor } \\
\text { and Bachelor } \\
\text { of Fine Arts } \\
\text { from MSU }\end{array}$ & $\begin{array}{l}\text { B.A. Art } \\
\text { Education and } \\
\text { B.F.A Print } \\
\text { Making }\end{array}$ & 5 & $\begin{array}{l}\text { Montana } \\
\text { Traditional } \\
\text { Games } \\
\text { Instructor } \\
\text { Certified }\end{array}$ & $\begin{array}{l}\text { Pursuing } \\
\text { Dual Master } \\
\text { of Arts - } \\
\text { Native } \\
\text { American } \\
\text { Studies and } \\
\text { Fine Arts }\end{array}$ & $\begin{array}{l}\text { Parent } \\
\text { of } 3\end{array}$ \\
\hline
\end{tabular}

Together, they participated in the vast majority of the immersive experiences that contributed to their completion of the TEP, and now have successfully joined their respective profession or continued their education, while remaining active members of the organization. In addition to being actively involved in the SINE, the members were also involved in the AIC and three of them held leadership roles and served on the AIC Executive Council. They all held 
different positions in the SINE at varying times. Notable is the fact that the youngest member was elected to serve as the student advisor/mentor once the SINE became an official MSU student organization.

Since members meet regularly and have travelled and spent a lot of time together outside of school, the SINE has become a close family. The SINE members are always willing to come to the aid of each other whenever they need help with anything including babysitting, helping with moving, loaning money, providing rides to meetings/appointments, etc. We celebrated milestones including graduation with coveted Pendleton graduation stoles. We have included members' families and community members in our events to widen the circle of support.

This group has been my saving grace. My first two years here I was working multiple jobs and my academics suffered. I was working on getting my GPA back up when I joined the SINE group. I had not expected much from this group or much of my own participation either. Yet, I helped present at a conference and it was talking about my experiences as a Native student on a predominately white campus and how that has affected my life. We all became very close as we presented and met up more. A year later I was asked to become the student advisor and without hesitation I accepted the position. I believe in this group so much. Every member has so much untapped potential and I want to see them find it and be able to use it. I would do anything for them and I know they would do the same. (SINE member, Brock)

\section{The SINE Professional Development Activities}

The SINE focused on discipline-specific initiation into the field of education with opportunities to write proposals, plan presentations and attend, present at, and network with educators at local and regional conferences as well as at national and international conventions. The SINE members were often the only undergraduate students presenting at the numerous conferences we attended including: the Montana Indian Education Association (MIEA) annual conferences, the National Indian Education Association (NIEA) conventions, the International Conference on Teaching, Learning and Student Success 2016 (ICTLSS'16), and the Indian Education for All (IEFA) Best Practices conferences. We also crafted a proposal for the World Indigenous Peoples Conference on Education (WIPCE) which attracts highly regarded experts and scholars in Indigenous education engaging representatives from First Nations (Canada), Native Americans (USA), Aborigines (Australia), Maori (New Zealand), Ainu (Japan), Sami (Norway) and more. We did major fundraising to procure the $\$ 19,000$ so that six SINE members could make the trip to present at WIPCE in Toronto.

Table 2. The SINE members presentations at conferences.

\begin{tabular}{|c|c|c|c|c|c|c|}
\hline Date & Presentations & Brock & Wilma & Frank & Ryan & Franny \\
\hline & \multicolumn{6}{|l|}{ Institutional } \\
\hline 2014 & $\begin{array}{l}\text { MSU Dept. of Education Presentation, } \\
\text { Bozeman, MT }\end{array}$ & $\mathrm{x}$ & $\mathrm{x}$ & & $\mathrm{x}$ & $\mathrm{x}$ \\
\hline \multirow[t]{2}{*}{2017} & $\begin{array}{l}\text { MSU IEFA Professional Development } \\
\text { Workshop, Bozeman, MT }\end{array}$ & $\mathrm{x}$ & $\mathrm{x}$ & $\mathrm{x}$ & $\mathrm{x}$ & $\mathrm{x}$ \\
\hline & \multicolumn{6}{|l|}{ Regional } \\
\hline 2014 & MEA/MFT, Missoula, MT & & $\mathrm{x}$ & $\mathrm{x}$ & $\mathrm{x}$ & $\mathrm{x}$ \\
\hline 2017 & MEA/MFT, Missoula, MT & $\mathrm{x}$ & $\mathrm{x}$ & $\mathrm{x}$ & & $\mathrm{x}$ \\
\hline 2018 & MFPE, Billings MT & $\mathrm{x}$ & $\mathrm{x}$ & $\mathrm{x}$ & & $\mathrm{x}$ \\
\hline 2015 & MIEA, Billings, MT & $\mathrm{x}$ & $\mathrm{x}$ & $\mathrm{x}$ & $\mathrm{x}$ & $\mathrm{x}$ \\
\hline 2018 & MIEA, Billings, MT & & $\mathrm{x}$ & $\mathrm{x}$ & & \\
\hline 2016 & IEFA Best Practices, Billings, MT & $\mathrm{x}$ & $\mathrm{x}$ & $\mathrm{x}$ & $\mathrm{x}$ & $\mathrm{x}$ \\
\hline 2017 & IEFA Best Practices, Helena, MT & $\mathrm{x}$ & & & & $\mathrm{x}$ \\
\hline \multirow[t]{2}{*}{2018} & IEFA Best Practices, Helena, MT & $\mathrm{x}$ & $\mathrm{x}$ & $\mathrm{x}$ & $\mathrm{x}$ & $\mathrm{x}$ \\
\hline & \multicolumn{6}{|l|}{ National } \\
\hline 2015 & NIEA - Portland, OR & $\mathrm{x}$ & $\mathrm{x}$ & $\mathrm{x}$ & $\mathrm{x}$ & $\mathrm{x}$ \\
\hline 2016 & NIEA - Reno, NV & $\mathrm{x}$ & $\mathrm{x}$ & $\mathrm{x}$ & $\mathrm{x}$ & $\mathrm{x}$ \\
\hline \multirow[t]{2}{*}{2018} & NIEA - Hartford, CT & $\mathrm{x}$ & $\mathrm{x}$ & $\mathrm{x}$ & & $\mathrm{x}$ \\
\hline & \multicolumn{6}{|l|}{ International } \\
\hline 2016 & ICLTSS - Bozeman, MT & $\mathrm{x}$ & $\mathrm{x}$ & $\mathrm{x}$ & & $\mathrm{x}$ \\
\hline \multirow[t]{2}{*}{2017} & WIPCE - Toronto, CA & $\mathrm{x}$ & $\mathrm{x}$ & $\mathrm{x}$ & $\mathrm{x}$ & $\mathrm{x}$ \\
\hline & Certification & & & & & \\
\hline $\begin{array}{l}2015 \\
2016\end{array}$ & $\begin{array}{l}\text { Montana Traditional Games Trainer } \\
\text { Certification, East Glacier, MT }\end{array}$ & & $\mathrm{x}$ & $\mathrm{x}$ & $\mathrm{x}$ & $\mathrm{x}$ \\
\hline
\end{tabular}


MSU - Montana State University

MEA/MFT - Montana Education Association/Montana Federation of Teachers MIEA - Montana Indian Education Association

MFPE - Montana Federation of Public Employees *Formerly MEA/MFT IEFA - Indian Education for All NIEA-National Indian Education Association

ICLTSS - International Conference on Learning, Teaching, and Student Success WIPCE - World Indigenous Peoples Conference on Education

The SINE faculty advisor/mentor then invited the SINE members who attended WIPCE to share their experiences and present at the IEFA professional development workshop for the MSU community and she was so proud of the polished panel discussion and PowerPoint presentation they prepared (see Table 2).

\section{The SINE Differentiated Supports}

We provided financial supports to the SINE members including: work study and other employment opportunities, scholarships, travel grants, fundraising, emergency loans, and we offset program additional fees (finger printing, CPR training, background checks, Praxis exams, etc.). We have offered opportunities for specialized training on Indigenous Traditional Games, organized visits to support members during their student teaching assignments and job placement phases of their career journeys, as well as focused on challenges and successes to integrating IEFAacross the curriculum.

In order to provide a culturally congruent, discipline-specific, mentoring program for all SINE members, the faculty advisor/mentor employed differentiated strategies to address individualized needs in addition to providing programming to meet the needs of the group as a whole. Specifically, the faculty advisor engaged individual students in conducting and presenting research at additional national and international conferences; served as a McNair Scholars Program mentor to several SINE members; taught an independent study course for a SINE member; hired them as work-study students; and provided them with higher order employment opportunities to exercise or build their knowledge and skills.

\section{The SINE and the 5 Rs}

\section{Respect}

Reflecting back on the strengths of the SINE mentoring program, it became apparent that Kirkness and Barnhardt's (1991) 4Rs and Wilson's (2008) fifth R, relationality, are critical elements to the group's success in creating cultural congruency. The SINE members all shared ways they felt respected, i.e. listened to and heard by each other. Through numerous storytelling opportunities members felt that their life experiences were validated, and their cultural heritages were valued. This was in contrast to many of their experiences participating in their TEP courses. For example, the SINE members, Wilma and Brock, emphasize the lack of respect and the feeling of disequilibrium this created as evidenced in the following quotes.

My teacher preparation coursework ignored my cultural heritage and life experiences throughout the entirety of my program through either varying degrees of silencing my voice, generalizing my culture, forcing colonized and pan-Indian stereotypes upon me, to even committing educational retaliation. SINE honored my cultural heritage by providing me space to be seen and heard through sharing my unique Nations' knowledge. SINE helped me navigate the expectations at a PWI with sharing in and overcoming similar issues we uniquely faced as Indigenous students. (SINE member, Wilma)

When looking at the content of the coursework, my cultural heritage was represented and received in two different ways: romanticized or as a complete lie. While some things were factually true, the way information was presented turned murder and genocide into a polite political disagreement. Other things were just complete lies based on personal bias and/or lack of knowledge. When looking at the social/political climate of the coursework, my cultural heritage and life experiences were also looked at in two different ways: I was seen as the Indigenous Expert or the Angry Indian. SINE offered the social climate to explore my Indigenous identity and knowledge in a respectful manner. (SINE member, Brock)

\section{Relevance}

Even in a state where IEFA is a constitutional mandate and there have been efforts to embrace Indigenized research methodologies, the opportunities for true relevance is rarely experienced by AI/AN students. At a PWI that has few Indigenous educators in faculty and staff positions, it was important for the SINE members to network with other Indigenous scholars. Having the opportunity to meet with Indigenous peoples within Montana, across the United States, and around the world allowed the SINE members to reaffirm their own worldviews. 
SINE facilitated many friendships for me. It was really meaningful to work hard with other Native education majors and become friends while achieving our goals and supporting each other by sharing our stories. The supportive family we built helped me to feel that my story was valuable and the experience of presenting that story to other educators helped me to find confidence in myself. It was also an incredible opportunity to meet fellow educators from around Montana, the US, and the world! Hearing their stories became more valuable to me than sharing my own. (SINE member, Ryan)

SINE really reintroduced my Indigenous identity back into my life and gave me opportunities to own it, not only as my own, but as a part of who I am. Insight from fellow members' cultures and knowledge of their own tribes fostered curiosity into my own cultural heritage. SINE aided in the process of breaking down my own internalized oppression. (SINE member, Brock)

\section{Reciprocity}

Reciprocity involves the sharing of knowledge and the recognition that individuals' differing perspectives need to be included in our collective consciousness. This was evident when exploring the Seven Essential Understandings that serve as a framework for IEFA. Being invited to present for K-12 teachers across the state of Montana at the IEFA Best Practices Conferences provided the SINE members with a chance to articulate their unique perspectives on the integration of past and contemporary Indian contributions to the K-12 core curriculum while hearing others' perspectives.

The things I enjoyed about SINE the most were getting to know the members, growing as a person, learning new things, and most importantly being an advocate for IEFA. (SINE Member, Frank)

Knowing about the policies, programs, standards, and expectations of the PWI was another source of knowledge that the SINE members were able to share.

Each member had knowledge of a certain part of the 'roadmap' and together, as SINE, we had knowledge of where we were and where we were going. Critical knowledge or "street smarts" of how to proceed through the PWI was shared within the group that only made every member more prepared to succeed within the system. (SINE member, Brock)

\section{Responsibility}

Acknowledging the innate responsibility Al/AN students feel to support the wellbeing of their families and communities, and to honor the memory of their ancestors often results in acts of advocacy. Providing the SINE members with the tools to speak up when confronted with social injustices and educational inequities served as a catalyst for their decision-making process as evidenced in the quotes below.

SINE has prepared me to always keep firm to my integrity even if it costs me everything and SINE showed me how important it is to fight hard for what you want because your hard work will not always equal success. (SINE member, Wilma)

As the first in my family to attend college, I am the caretaker of my family. I have responsibilities beyond what other "normal" college students have. When needing to go home or take a call during class, professors and peers were never understanding or accommodating. Nonetheless, I have developed not only the necessary skills to enter the teaching field, but to also succeed within it. Through this group, I have learned to critically analyze everything from lesson plans and curriculum to the very institution that taught me these skills. I have learned to communicate feedback, offer solutions, and foster accountability within myself, to my peers, and to my institution. I feel SINE has prepared me so much that I feel confident in offering over my professional knowledge and skills to even better prepare future Indigenous educators as they prepare to enter the teaching field. (SINE member, Brock)

\section{Relationality}

Although we recognize that the 4Rs laid out by Kirkness and Barnhardt (1991) all play a significant role in the success of the SINE culturally congruent, discipline-specific mentoring program, we recognize that relationality, as described by Wilson (2008), is of paramount importance. All SINE members share this sentiment as evidenced in the quotes integrated throughout this article and highlighted by Franny, Ryan, and Brock here.

SINE is an environment where everyone is invested in everyone's success, whatever that means for that person. From lending gas money to reviewing important assignments, we helped each other navigate the expectations at a PWI. (SINE member, Franny)

... definitely the relationships! It's been amazing getting to know my peers in similar fields and build a sort of family with you guys. The faculty advisor is such an incredible person! Getting to know and work with her has really enriched my life both professionally and personally. (SINE member, Ryan)

Like many other people of color, we experience battle fatigue within a PWI. It was nice to have fellow warriors there who knew what it meant to pick a battle to fight or not. Sacrifices of critical time, energy, and resources would have to be made in order to face a battle. This sacrifice was lessened with the wisdom and influence of the mentor/advisor. She knows and suggests various avenues we could take 
and supported us in whichever one we chose. Thanks to this group, I went from being passively Indigenous to being unapologetically Indigenous. (SINE member, Brock)

\section{Discussion}

For mentoring programs to be successful, an institutional commitment from top level administrators, special staffing, as well as role models and allies are necessary. With established support in place, key players in the mentoring program can focus on programming. The role of the faculty advisor/mentor, the student advisor/mentor and the student members are of equal and paramount importance. Serving as a faculty advisor/mentor for undergraduate research, scholarship, and creative work is a challenging but very rewarding experience. Mentors need a repertoire of knowledge and capacities to support novices' induction into the field of teaching. In addition to serving as an ally, faculty mentors must actively model and engage in advocacy for students. Relative to their mentees, mentors should have more experience, influence, or achievement within the educational environment, and they need to exercise this power to ensure that educational equity and social justice are realized. As a faculty advisor/mentor, it is crucial to help students navigate the university context by helping them develop a constellation of supporters by connecting to other campus and community resources and allies (Windchief \& Brown, 2017). It is also important to recognize the stresses pre-service teachers face and offer suggestions/ideas on how to overcome their anxiety and support their growth.

The role of the student advisor/mentor of a culturally congruent, discipline-specific mentoring program is a demanding and transformative opportunity. The student advisor /mentor requires an in-depth understanding of many different aspects of the PWI. Whether from personal experience or with the guidance of the faculty advisor/mentor, the student advisor/mentor needs to be available and willing to answer all questions, provide last minute support, and establish the connection between members and resources. As a student advisor/mentor, it is vital to develop the ability to bridge the communication gap between Native and non-Native counterparts. One must be able to recontextualize thoughts, ideas, and feedback to ensure comprehension and diminish miscommunication. The student advisor/mentor is to act as a source of validation, engagement, and empowerment for Al/AN students.

The commitment of general members within this type of group is integral for the success of each member and the group as a whole. Like many other student support groups, we have official student leaders. Yet unlike other student groups, every member has equal influence and power when it comes to offering ideas, providing feedback, and proposing direction. This equity among the members created a heightened sense of belonging, elevated personal buyin, and magnified collective self-esteem. With the guidance of the faculty advisor/mentor and the facilitation by the student advisor/mentor, members are given the chance to edit, approve, or even completely scratch any part of a presentation proposal, meeting agenda, event outline, fundraising effort, etc. Members took full advantage of this liberty and responsibility to further their professional development through collaboratively aiding in outlining new presentations, seeking alternative fundraising avenues, and planning different events. A unique approach such as this fostered something more than just a group: it fostered a family dynamic, i. e., the making of relatives. During official meetings and workshops, members engaged in teasing and inside jokes all while maintaining their professional integrity. Within this family, each member's individual successes, failures, and dreams transformed into the group's successes, failures, and dreams.

In higher education institutions, only $.4 \%$ of faculty on college campuses are $\mathrm{Al} / \mathrm{AN}$ (Huffman, 2011). Consequently, it is unlikely that Al/AN students will have an Al/AN faculty mentor in the leadership position of their culturally congruent, discipline-specific mentoring group, as is the case here. Therefore, it is imperative that, in addition to faculty mentors being committed to providing developmental support to students and helping them navigate institutional, departmental, and programmatic requirements, they need to also possess the ability to be culturally responsive. Faculty mentors need to be aware of the worldview of Al/AN students who may come from more assimilated cultural backgrounds as well as the worldview of those with traditionally held $\mathrm{Al} / \mathrm{AN}$ values and beliefs. It is significant in the success of all of these students, that the faculty mentor does not express bias but rather, understands the social context of all Al/AN students, and the need for family-based 
education in institutions of higher learning. The ultimate goal of the SINE was to develop discipline-specific knowledge, skills and abilities in pre-service teachers to increase their confidence. Through intentional and ongoing interactions with a discipline-specific mentor the SINE members were provided networking opportunities with other Indigenous educators from around the globe in various stages in their careers.

Being a faculty mentor transcends assigned roles such as academic advisor and teacher. We suggest here a dramatic redefinition of the role of faculty advisors/mentors who want to embrace culturally congruent, discipline-specific mentoring for Al/AN students by advocating for educational equity and social justice. As is, the status quo falls short at best, and in many circumstances diminishes Al/AN students' chances for persistence and completion. The recommendation we have for selecting a faculty advisor/mentor to work with Al/AN students would be to select someone with the following attributes: 1). Experience and expertise in mentoring strategies and how to support novices' growth, 2). Experience and an understanding of best practices working with Al/AN students, families and communities, 3). Expertise as a K-12 classroom teacher - unique requirements for content specific mentoring is preferred but having a general broadfield knowledge of the role of a classroom teacher is very helpful, 4). Establish and nurture a network of Indigenous educators, scholars, legislators, community members who may serve as experience and wisdom bearers, 5). Embrace culturally responsive pedagogy by conducting research, outreach, and teaching on IEFA specifically or Indian education in general, 6). Facilitate pre-service teachers' transition into seasoned professionals, 7). Support collaboration with the students' other mentors on and off campus including financial aid representatives, the Dean of students, the registrar, faculty in Native American Studies, staff in American Indian Council, licensure department placement personnel, members of other student organizations, and cooperating teachers, university supervisors, members of professional organizations, etc.

Thank you! Thank you for everything, thank you for helping me get the experience and confidence through presentations. Thank you for taking me places I wouldn't have gone on my own. And thank you for being someone who stands up for what is right. Thank you for believing in me even at times I didn't believe in myself. (SINE member, Frank)

The recommendation we have for choosing a student advisor/mentor to lead a culturally congruent, discipline-specific mentoring program would be to engage someone in this role who can: 1). Model persistence when facing personal, academic, and professional obstacles, 2). Showcase an in-depth understanding of the many facets of the PWI including: academic support services, student engagement, financial aid, and diversity initiatives, 3). Share a common Al/AN worldview and life experiences with group members 4). Possess technological and communication skills, 5). Demonstrate strong organizational and leadership skills, and 6). Facilitate communication and collaboration with the faculty advisor/mentor.

Investing in the success of future teachers can be an enriching experience for faculty and student advisors/mentors as well as for the mentoring program members. Interacting with novice students who more often than not have numerous questions and face obstacles, becomes a reinvigorating experience. By creating a home away from Home for students, you can create a sense of belonginess and you may nurture a familial relationship that develops into a lifetime friendship.

\section{Conclusion}

Culturally congruent, discipline-specific mentoring can effectively support Al/AN students' adjustment to college, motivation, efficacy, career development, leadership skills, persistence, and degree completion. The SINE mentoring program was created to support the recruitment, retention, graduation, placement and on-going support of Al/AN students interested in becoming K-12 classroom teachers. The abysmal statistics on AI/AN students in the $\mathrm{K}-12$ system and higher education environments, as well as the Al/AN pre-service teachers and other educators in the teaching profession shared here, and the description of factors that can contribute to student success can be addressed by providing students with culturally congruent, discipline-specific mentoring. In doing so, the experiences and out-. 
comes for $\mathrm{Al} / \mathrm{AN}$ pre-service teachers would be positively impacted when they graduate and are successfully inducted into the teaching field. Furthermore, this increase of Al/AN teachers will create a ripple effect such that, they will immediately be a support to their professional peers, serve as role models for Al/AN K-12 students, and provide mentoring to future, aspiring $\mathrm{Al} / \mathrm{AN}$ pre-service teachers.

Student members benefit from participating in support groups like the SINE in many ways. By working with an experienced faculty advisor/mentor who knows the requirements and expectations of 'surviving and thriving' in the teacher preparation program, students can avoid common pitfalls related to high expectations, strict deadlines, trying bureaucracy, excessive paperwork, and challenging schedules as well as other barriers that could derail their efforts. Experiencing a speedier adaptation to the requirements, expectations, deadlines, etc. is a great advantage for any student, and especially students who are often invisible in PWIs.

The experiences of the SINE members should raise questions and challenge previously held assertions regarding best practices for the creation of support groups for AI/AN and other 'minoritized' students in institutions of higher learning. By participating in the SINE, the faculty and student advisors/mentors offer the mentees helpful information, suggestions, and even introduce them to others who can be helpful on campus. Recent mentoring scholarship provides a more complex understanding of mentoring as a means for promoting social justice and educational equity in higher education. By focusing on student groups that have been historically understudied and underserved in universities across the country, culturally congruent, discipline-specific mentoring can have a positive impact on Al/AN mentees' competence and effectiveness and can help build their self-confidence.

Among other relational benefits, friendship has been an outcome for the SINE members that is expected to be of long-term benefit that has served as a foundation for the making of relatives that is at the heart of the SINE. We recognize that our AI/AN future teachers are essential to the implementation of Indian Education for All in a culturally responsive manner in the K-12 system and beyond. Without their unique contributions we will never realize the inclusive spirit that Indian Education for All embodies. It was important to us that this article be crafted in the spirit of such collaboration.

\section{Appendix A}

\section{MSU Initiative Highlights and Accomplishments}

Montana State University (MSU), a land grant institution, has set a new enrollment record. Of the 16,702 students enrolled during the fall 2018 semester, 776 were American Indian. These figures mark 11 straight years of enrollment growth for the Bozeman campus. Founded in 1893, MSU is currently commemorating its $125^{\text {th }}$ anniversary and has a lot to celebrate. During the 2018 Indigenous People's Day celebration on campus, President Waded Cruzado shared exciting news. Thanks to an extremely generous $\$ 12$ million pledge from the Kendeda Fund, a private foundation with a long history of supporting conservation and community-led projects in Montana, plans for a state-of-the-art, \$20 million American Indian Hall are underway. The new building will be a place where American Indian students can learn and teach about their cultures, not only with each other, but with their peers across campus.

MSU's American Indian/Alaska Native (AI/AN) students are representative of over 60 distinctive tribal nations. All of these students are important to the fabric of what makes MSU an institution of choice for Al/AN students and several recent graduates are trailblazers. Nick Ross Dick (Yakama) was the first Native student to be elected to the ASMSU student government and to run for student body president. Leo and Steven Davis (Blackfeet) are 2 of 5 brothers in a legacy family. Their parents met in the AIC at MSU and all 5 brothers excel in academics and athletics. Leo was a top Montana recruit and a standout football player at MSU, and Steven majored in chemical and biochemical engineering, and was a forward for the MSU men's basketball team. Although both were offered scholarships to numerous institutions, they let their loyalty to MSU play out. Montana Wilson (GrosVentre) was the recipient of the prestigious Gates Cambridge and Udall Scholarships. Emery Three Irons (Crow) was also a winner of the prestigious Udall Scholarship and he was honored in the Tribal Public Policy category, with a scholarship from the National Institute of Environmental Health Sciences (NIEHS). Yet among all of these accomplishments, the recruitment, retention, and graduation of American Indian students is still a concern. 
The Native American Studies (NAS) department at MSU offers an interdisciplinary program of study in American Indian culture and history, policy and law, community affairs, education, through a non-teaching minor in NAS, an online graduate certificate in NAS, a Master of Arts in NAS, as well as opportunities for all MSU undergraduate students to gain a multicultural perspective in meeting the university's core curriculum requirements. The NAS department was established to provide and advance quality education for and about American Indians of Montana, the region, and the nation. Consistent with its service commitment to Montana's tribal communities, much of the faculty's research responds to the educational, cultural, and economic development needs in Indian country as identified by the tribes. In addition to the traditional functions of an academic department, NAS places a high priority on providing student support programs and services, reflecting a strong commitment to Al/AN student retention and success.

MSU currently boasts the highest retention rate of Native students in the Montana University System. No matter which college they are admitted in, or what major they declare, Native students recognize the NAS department as their home. Housed in the NAS department, American Indian Council (AIC), the oldest Al/AN student organization on campus, has been in existence for over 60 years. The AIC was established to: recruit high school and transfer students to attend MSU; assist new students in their adjustment to college life; provide an environment that respects and promotes scholarship in accordance with students' cultures and customs; work with students through promotion of extra-curricular activities that bridge MSU with the Gallatin Valley and its American Indian residents (AIC By Laws, 2014).

The AIC has always had strong leadership. In fact, the first 55 years of AIC's existence, the organization had only two remarkable individuals in the Director of Al/AN Student Success Services position. The AIC offers academic advising, personal counseling, inspiration and hope to American Indian students. The following is a list of the comprehensive services and resources AIC provides to promote students' academic success: academic advising, group and individual tutoring, academic grade monitoring, study groups, financial aid advocacy, community outreach, scholarship support, community resource support, campus advocacy, child care referral, emergency loans, as well as walk-in counseling sessions, special sections of core courses in the fundamentals of writing and literature and computer lab access, free printing, copy service, fax machine, scanning and phone services. In addition, the AIC, a not for profit organization, supports the American Indian Council Student Organization which provides leadership opportunities for students to serve on the AIC student led Executive Council.

In addition, the AIC is responsible for the success of the numerous cultural events which are held throughout the academic year to highlight the great work being done by MSU students, faculty and staff who are working on behalf of American Indian, Alaska Native, Native Hawaiian, First Nations, and similar Indigenous communities. These include: the Annual American Indian Council Powwow, Annual American Heritage Day celebration, Indian Education for All professional development workshops, Indigenous People's Day celebration, Native Pathways to Success Student Orientation, as well as the numerous student and family gatherings, meals, holiday celebrations, and many other cultural events to support students.

Here we highlight some of the culturally congruent, discipline-specific mentoring programs at MSU: EMPower, AIRO, MAP, and COOP. Operated through the College of Engineering, EMPower provides student support for all underrepresented students in the STEM (science, technology, engineering, mathematics) fields and houses the American Indian Research Opportunities (AIRO) which focuses on science, engineering and math. The AIRO Bridges program works with the seven Tribal Colleges within Montana to recruit, retain, and graduate American Indian students who transfer from Tribal Colleges. AIRO actively pursues tribal college students because as Boyer (1997) found “... American Indian students who had attended a tribal college before transferring to a four-year institution were four times more likely to complete a four-year degree than those who entered a mainstream institution as freshmen (p.35)". One of AIRO's efforts includes providing an eight-week summer program, Bridges to the Baccalaureate, where participants engage in academic activities and research with faculty mentors and lab teams. The goal of this program is to provide a stronger educational bridge for students transferring from a two-year tribal college to MSU and ensuring student academic success within the studies of biomedical, behavioral health, and/or other health related science. 
In addition, the Montana Apprenticeship Program (MAP) brings Native high school junior and senior students to campus to spend 6-weeks hands-on summer research experience to encourage them to pursue careers in STEM fields skilled, culturally competent nursing corps. On average, five students complete the program each year; to date 100+ individuals have successfully completed the program. CO-OP was designed to support American Indian students who were pursuing a nursing degree and therefore, improve health care in Indian country by diversifying the nursing pool. Even though the American Indian/Alaska Native population is on the rise, health disparities persist and Native nurses are gravely underrepresented in the professional nursing field. In order to help American Indian/Alaska Native nursing students successfully complete their academic training, CO-OP provides supplemental, culturally sensitive academic advising, academic tutoring, community building and networking, specialized seminar/workshops, testing support for the National Council Licensure Examination (NCLEX), resume writing, job placement, and financial support through stipends. During the 2017-2018 academic year, CO- OP implemented the extended family model (Joseph, \& Sweeney, 2017).

MSU continues to identify ways that it can better support AI/AN students.

\section{References}

Achinstein, B. \& Davis, E. (2014). The subject of mentoring: Towards a knowledge and practice base for content-focused mentoring of new teachers. Mentoring \& Tutoring Partnership in Learning, 22 (2), 104-126.

Benjamin, D.P., Chambers, S., \& Reiterman, G. (1993). A focus on American Indian college persistence. Journal of American Indian Education, 32 (2), 24-40.

Bernard, H. R. (2012). Social research methods: Qualitative and quantitative approaches. Sage. Bettencourt, B. A., Charlton, K., Eubanks, J., Kernahan, C., \& Fuller, B. (1999). Development of collective self-esteem among students predicting adjustment to college. Basic and Applied Social Psychology, 21 (3), 213-222.

Brown, L. L. (1997). Psychosocial factors influencing academic persistence of American Indian college students. Journal of College Student Development, 38 (1), 3-12.

Bruce, M., \& Bridgeland, J. (2014). The mentoring effect: Young people's perspectives on the outcomes and availability of mentoring. A report for MENTOR: The national mentoring partnership. Civic Enterprises. Retrieved from: http://www.mentoring.org/images/uploads/Report_TheMentoring Effect.pdf.

Cleary, L. M., \& Peacock, T. D. (1998). Collected wisdom: American Indian education. Boston: Allyn and Bacon.

Collier, P. J. (2015). Developing effective student peer mentoring programs: A practitioner's guide to program design, delivery, evaluation, and training. Sterling, VA: Stylus Publishing.

College Board Advocacy \& Policy Center. (2013). The college and completion agenda 2012 progress report. 130505271 12b-6368. Retrieved from: http://media.collegeboard.com/digitalServices/ pdf/advocacy/policycenter/college-completion-agenda-2012-progress-report.pdf

Creswell, J. W. (2014). Research design: Qualitative, quantitative and mixed methods approaches (4 $4^{\text {th }}$ ed.). Thousand Oaks, CA: Sage.

Creswell, J. W.; Hanson, W. E.; Plano Clark, V. L. \& Morales, A. (2007). Qualitative research designs: Selection and implementation. The Counseling Psychologist, 35(2), 236-264. doi: 10.1177/ 0011000006287390

Denzin, N. K. \& Lincoln, Y. S. (2011). Introduction: The discipline and practice of qualitative research. In Norman K. Denzin \& Yvonna S. Lincoln (Eds.), The Sage handbook of qualitative research (4t $\mathrm{t}^{\mathrm{h}}$ ed., pp.1-20). Thousand Oaks, CA: Sage.

Executive Office of the President. The White House. United States Government. (2014a). My Brother's Keeper Task Force Report to the President. Retrieved from

:https://obamawhitehouse.archives.gov/sites/default/files/docs/053014_mbk_report.pdf

Executive Office of the President. The White House. United States Government. (2014b). 2014 Native Youth Report. Retrieved from:

https://obamawhitehouse.archives.gov/sites/default/files/docs/20141129nativeyouthreport_final.pdf 
Harrison, H., Birks, M., Franklin, R., and Mills, J. (2017). Case study research: Foundations and methodological orientations. Retrieved from:http://www.qualitative-research.net/index.php /fqs/article/ view/2655/4079

HeavyRunner, I. \& DeCelles, R. (2002). Family Education Model: Meeting the student retention challenge, Journal of American Indian Education, 41(2), 29-37.

HeavyRunner, I. \& Marshall, K. (2003). Miracle Survivors: Promoting resilience in Indian students. Tribal College Journal, 14(4), 14-18.

Hoffmann, L. L., Jackson, A. P., \& Smith, S. A. (2005). Career barriers among Native American students living on reservations. Journal of Career Development, 32(1), 31-45.

Huffman, T. (2001). Resistance theory and the transculturation hypothesis as explanations of college attrition and persistence among culturally traditional American Indian students. Journal of American Indian Education, 40 (3), 1-23.

Huffman, T. (2011) Plans to live on a reservation following college among American Indian Students: An examination of transculturation theory. Journal of Rural Education. 26(3), 1-13.

Jackson, A.P., Smith, S.A., \& Hill, C.L. (2003). Academic persistence among Native American college students. Journal of College Student Development, 44(4), 548-565.

Joseph, D.H. \& Windchief, S. (2015) Nahongvita: A conceptual model to support rural American Indian youth in pursuit of higher education. Journal of American Indian Education, 54 (3), 76-97.

Kirkness, V. J. \& Barnhardt, R. (1991). First Nations and higher education: The four Rs-respect, relevance, reciprocity, and responsibility. Journal of American Indian Education, 30 (3), 1-15.

LaFromboise, T. D., Hoyt, D. R., Oliver, L., \& Whitbeck, L. B. (2006). Family, community, and school influences on resilience among American Indian adolescents in the upper midwest. Journal of Community Psychology, 34 (2), 193-209. doi:10.1002/jcop.20090.

Lomawaima, K. T. (1995). Educating Native Americans. In J. A. Banks \& C. A. M. Banks (Eds.), Handbook of Research on Multicultural Education (pp. 331-347). New York: Macmillan.

Marroquin, C. \& McCoach, D. B. (2014). Measuring cultural integrity through the lens of transculturation: Psychometric properties of the North American Indigenous college students' inventory (NAICSI), presented at the American Education Research Association annual conference.

Montana Office of Public Instruction, (2018). Growth and Enhancement of Montana Students. Graduation Dashboard Retrieved from: https://gems.opi.mt.gov/StudentCharacteristics/Dashboards/Graduation \%20Dashboard/Graduation\%20Dashboard.aspx

Montana Office of Public Instruction, (2018). Montana American Indian student achievement data report, Fall 2018. Retrieved from: https://opi.mt.gov/Portals/182/Page\%20Files/Indian\%20 Education/Indian \%20Student\%20Achievement/Docs/Data\%20Report\%202018.pdf?ver=2018-09-13-100309-773

Montana Code. Annotated. Title. 20, ch.1, pt. 5, § 1. Indian Education for All.1999. Montana Constitution Article. X, §1.

Mosholder, R. S., Waite, B., Larsen, C. A. \& Goslin, C. (2016). Promoting Native American college student recruitment \& retention in higher education. Multicultural Education, Spring/Summer, 27-36.

Mosholder, R. \&Goslin, C. (2013). Native American college student persistence. College Student Retention, 15 (3),305-327.

Murguia, E., Padilla, R. V. \& Pavel, M. (1991). Ethnicity and the concept of social integration in Tinto's Model of Institutional Departure. Journal of College Student Development, 32, 433-439.

Pewewardy, C. (2008). Learning styles of American Indian/Alaska Native students. In J. Noel (Ed.), Classic edition sources: Multicultural education(pp.116-121). New York: McGraw-Hill.

Shotton, H. J., Oosahwe, E. S. L. \& Cintrón, R. (2007). Stories of success: Experiences of American Indian students in a peer-mentoring retention program. The Review of Higher Education, 31(1), 81-107. Retrieved from: :https://muse.jhu.edu/

Snow Andrade, M. (2014). The successful educational journeys of American Indian women: Forming aspirations for higher education. International Journal of Multicultural Education, 16 (1), 21-38.

Stake, R. E. (1978). The case study method in social inquiry. Educational Researcher, 7(2), 5-8.

Stake, R. E. (1995). The art of case study research. Thousand Oaks, CA: Sage Publications, Inc. Tachine, A. R., Cabrera, N. L. \& Yellow Bird, E. (2017). Home away from home: Native American students' sense of belonging during their first year in college. The Journal of Higher Education, 88

(5), 785-807. 
Tate, D. S., \& Schwartz, C. L. (1993). Increasing the retention of American Indian students in professional programs in higher education. Journal of American Indian Education, 33(1), 21-31.

Thornton, B. \& Sanchez, J. E. (2010). Promoting resiliency among Native American students to prevent dropouts. Education, 131 (2), 455-464.

Tierney, W.G. (1992). Official encouragement, institutional discouragement: Minorities in academe-The Native American experience. Norwood, NJ: Ablex.

Tinto, V. (1975). Dropout from higher education: A theoretical synthesis of recent research. Review of Educational Research, 45, 89-125.

Tinto, V. (1987). Leaving college: Rethinking the causes and curses of student attrition. Chicago, IL: University of Chicago Press.

Tinto, V. (1993). Leaving college: Rethinking the causes and cures of student attrition (2nd ed.).Chicago, IL: University of Chicago Press.

U.S. Department of Education. Office for Civil Rights. Civil Rights Data Collection (CRDC). (2014). 201314 Estimations for Enrollment. U.S. Department of Education. Washington, DC. Retrieved from:https://ocrdata.ed.gov/StateNationalEstimations/Estimations_2013_14

U.S. Department of Education. Institute of Education Sciences, National Center for Education Statistics. (2019a). Status and Trends in the Education of Racial and Ethnic Groups 2018 (NCES 2019-038). U.S. Department of Education. Washington, DC. Retrieved from: https://www.nces.ed.gov/

U.S. Department of Education. Institute of Education Sciences, National Center for Education Statistics. (2019b) Table 1. Public high school 4-year adjusted cohort graduation rate (ACGR), by race/ethnicity and selected demographic characteristics for the United States, the 50 states, and the District of Columbia: School year 2016-2017. Retrieved from: https://www.nces.ed.gov/

U.S. Department of Education. Institute of Education Sciences, Integrated Post-Secondary Data System. (2019c). U.S. Department of Education. Washington, DC: Retrieved from: https:// nces.ed.gov/collegenavigator/

U.S. Department of Education. Institute of Education Sciences, National Center for Education Statistics. (2018). Characteristics of Public Elementary and Secondary School Teachers in the United States: Results From the 2015-16 National Teacher and Principal Survey First Look (NCES 2017-072rev). U.S. Department of Education. Washington, DC: National Center for Education Statistics.

University of California, Davis. American Indian Recruitment \& Retention. (2018). Retrieved from: https://srrc.ucdavis.edu/airr-american-indian-recruitment-retention

Villalpando, O. (2003). Self-segregation or self-preservation? A Critical Race Theory and Latina/o Critical Theory analysis of a study of Chicana/o college students. Qualitative Studies in Education, 16 (5), 619-646.

Wexler, L. \& Burke, T. K. (2011) Cultural identity, multicultural competence and resilience: A pilot study of Alaska Native students' experience at university. Journal of American Indian Education, 50 (2), 44-64.

Wilson, S. (2008). Research is Ceremony: Indigenous Research Methods. Black Point, N.S.: Fernwood Pub.

Windchief, S. \& Brown, B. (2017). Conceptualizing a mentoring program for American Indian/Alaska Native students in the STEM field: A review of the literature. Mentoring \& Tutoring: Partnership in Learning, 25 (3), 329-345.

Yin, R. K. (2002). Case Study Research: Design, and Methods. (3 ${ }^{\text {rd }}$ ed.) Newbury Park: Sage Publications. 